\title{
A IMPORTÂCIA DA MENTALIDADE DE CRESCIMENTO PARA O ALCANCE DE OBJETIVOS
}

\author{
Israel Ribeiro Alves ${ }^{1}$
}

RESUMO: O presente artigo possui como objetivo verificar através de pesquisa bibliográfica além de artigos e dissertações sobre o tema a Importância do Desenvolvimento da Mentalidade de Crescimento para o Alcance de Objetivos, afim de demonstrar que o Mindset de Crescimento, é uma atitude voltada para o desenvolvimento e o aprendizado contínuo do indivíduo, fazendo com que ele contribua de forma sistêmica para a organização em que atua, potencializando os indivíduos a buscar um maior desempenho, engajamento e qualidade de vida. Quando o profissional toma consciência de que é ele quem controla a sua mente e não o contrário, é capaz de retrabalhá-la de forma que ela esteja sempre focada no positivo e pronta para enfrentar qualquer desafio em busca do sucesso. Este trabalho buscou analisar a relação entre o Mindset de crescimento, o Mindset fixo, uma vez que o indivíduo pode assumir uma atitude defensiva, focado em seu desempenho individual, como o Mindset Fixo de Desempenho e, por sua vez, evitar tarefas desafiadoras e que envolvam aprendizado e mudanças, como o Mindset Fixo Bloqueador, para as pessoas com essa mentalidade, a inteligência pode ser melhorada, elas podem aprender habilidades possibilitando de novos aprendizados para se alcançar o sucesso por meio dos esforços independe da idade, pessoas com mentalidade de crescimento podem aprender habilidades e novos aprendizados na possibilidade de se alcançar o sucesso por meio dos esforços, uma vez que aprendizado é independe da idade, pois está mais relacionado a querer e se esforçar.

Palavras-chave: Mentalidade de Crescimento. Qualidade de Vida. Aprendizado.

ABSTRACT: This article aims to verify, through bibliographical research, in addition to articles and dissertations on the topic, the Importance of the Development of the Growth Mindset to the Achievement of Goals, in order to demonstrate that the Growth Mindset is an attitude towards the development of continuous learning of the individual, making him/her to contribute in a systemic way to the organization in which he/she works, enhancing those necessary to seek greater performance, engagement and quality of life. When the professional becomes aware that he is the one who controls his mind and not the other way around, he is able to rework it so that it is always focused on the positive and ready to face any challenge in search of success. This work sought to analyze the relationship between the Growth Mindset, the Fixed Mindset, since the individual can

${ }^{\mathrm{I}}$ Administrador e consultor com registro no CRA-SC 28764, graduado no curso de administração de empresas pela Faculdade de Ciências Administrativas e Contábeis, centro universitário da grandes dourados, UNIGRAN. Pós-graduação em MBA executivo em administração com ênfase em recursos humanos, centro universitário da grandes dourados, UNIGRAN. cursando mestrado em administração, pela Must University (Florida- USA). 
assume a defensive attitude, focused on their individual performance, such as the Fixed Performance Mindset and, in turn, avoid challenging tasks that involve learning and change, like the Fixed Blocker Mindset, for people with this mindset, intelligence can be improved, they can learn skills enabling new learning to achieve success through ageindependent efforts, people with growth mindset they can learn skills and new learning in the possibility of achieving success through efforts, since learning is independent of age, as it is more related to wanting and making efforts.

Keywords: Growth Mindset. Quality of Life. Learning.

\section{INTRODUÇÃO /METODOLOGIA}

Este paper apresenta pesquisa investigativa através de websites, e bibliografia, por meio de artigos com o tema sobre a importância do desenvolvimento da mentalidade de crescimento para o alcance de objetivos, é notável que as mudanças fazem parte do cotidiano pessoal e organizacional, sendo que a mudança acaba nos tirando de nossa zona de conforto, e os indivíduos apresentam resistência a mudanças, sejam em menor ou maior escala, principalmente quando não é de uma escolha pessoal.

No ambiente organizacional intensificasse ainda mais, mesmo quando mudanças são necessárias e esperadas, parte da rotina, nesse sentido, o mindset fixo ou de crescimento das pessoas envolvidas exerce papel importante para determinar o nível de aceitação ou resistência dos colaboradores à mudança, para isso o desenvolvimento das qualidades básicas através dos próprios esforços tem que ser desenvolvendo através de ações por meio da disciplina e do trabalho duro, com a crença de que é possível desenvolver e alcançar as metas desejadas pelo processo de aprendizado, sendo que há vários tipos de personalidades que o ser humano dispõe, como sentimentos, e emoções distintas uma das outras.

Indivíduos e equipes possuem potencial para desenvolver um mindset de crescimento, para que tal desenvolvimento, exige deixar de lado crenças limitantes e errôneas sobre a vida.

Portanto, o objetivo é que o indivíduo tenha hábitos diários pequenos e positivos sobre a mentalidade para vencer desafios, afim de alcançar a excelência naquilo em que se exercita incansavelmente, repetindo à exaustão. 


\section{DESENVOLVIMENTO - REVISÃO DE LITERATURA}

\section{MENTALIDADE FIXA E MENTALIDADE DE CRECIMENTO}

A mentalidade fixa leva o indivíduo a crer que você é bom ou não em alguma coisa, com base em sua natureza inerente, já mentalidade de crescimento leva ao entendimento que alguém pode ser bom em qualquer coisa, porque suas habilidades são inteiramente devidas a suas ações.

De acordo com (DWECK, 2017). Uma das crenças mais básicas que se carrega, tem a ver com a forma como vemos e habitamos o que consideramos nossa personalidade.

Mentalidade fixa define que nosso caráter, inteligência e habilidade criativa são dados estáticos e não pode ser mudado de maneira significativa, para isso se esforçar pelo sucesso e evitar o fracasso a todo custo torna-se uma maneira de manter a sensação de ser inteligente ou habilidoso.

A mentalidade de crescimento, define-se pelo desafio como uma mola propulsora e encorajadora para o crescimento e para aumentar nossas habilidades existentes.

De acordo com (POPOVA, 2014). no ponto chave do que torna a "mentalidade de crescimento" tão relevante, Dweck, descobriu que ela cria uma paixão pela aprendizagem e não uma fome de aprovação, a convicção de que qualidades humanas como inteligência e criatividade, e até mesmo capacidades de relacionamento como amor e amizade, podem ser cultivadas através do esforço e da prática deliberada, pessoas com essa mentalidade não são desencorajadas pelo fracasso, elas realmente não se veem falhando nessas situações, eles se veem aprendendo.

Diante dessas duas mentalidades, a qual podemos manifestar desde uma idade muito precoce, brotam muito nosso comportamento, nossa relação com o sucesso e o fracasso profissionais e pessoais e, finalmente, nossa capacidade de felicidade.

\section{INFLUÊNCIA DA MENTALIDADE FIXA}

De acordo com (DWECK, 2017), as pessoas que possuem o Mindset fixo sentem a necessidade de mostrar suas competências e habilidades para seus colegas, como forma 
de autoafirmação, o que gera, a longo prazo, um afastamento das tarefas desafiadoras e de mudanças que penetrem em sua zona de conforto.

O ser humano tende naturalmente a escolher a solução mais cômoda, dedicando a maior parte do tempo a fazer atividades dentro da sua zona de conforto, um estado em que experimentamos segurança e bem estar e onde sentimos que temos o controle da situação.

As nossas emoções constantemente nos impulsionam em direção a essa zona de conforto, aquele que não precisa dispor de muito raciocínio, é automático, porém, se você deseja melhorar o seu desempenho, é um pré-requisito absoluto sair dela regularmente. $\mathrm{O}$ seu repertório de emoções positivas irá crescer se você simplesmente ousar dar um salto e comprometer-se de fato. Para tanto e para transformar esse tipo de comportamento em hábito, será preciso fazer-se as perguntas certas.

Dessa forma, pode-se aferir que pessoas com Mindset fixo se esforçam pelo sucesso, mas evitam o fracasso a todo custo, para que sua imagem de indivíduo exemplar evitando tarefas que possam vir a mostrá-las como indivíduos fracassados e com pouca habilidade.

\section{I Habilidades na mentalidade de crescimento}

Os indivíduos com Mindset de crescimento estão mais dispostos a lidar com a incerteza e aceitar os resultados indesejados, não temendo os desafios que surgiram para atingir seus objetivos. Portanto essas características auxiliam o indivíduo a desenvolver o Potencial Empreendedor e não ter receio em abrir seu negócio, refreando o entendimento de que o fato de o negócio não ter tido sucesso não o qualifica o indivíduo como alguém desprovido de habilidade e inteligência. Ele enxerga os obstáculos sob uma perspectiva de evolução cognitiva e, por meio do aprendizado, não se intimida em abrir seu próprio negócio, persistindo em seus objetivos, procurando sempre aprender com seus pares e com o ambiente ao seu redor.

De acordo com essa mentalidade, o esforço e a dedicação próprios poderão consistentemente levar uma pessoa a melhorar o próprio rendimento. A pessoa acredita que resultados negativos poderão ser modificados como consequência de esforço e treinamento. A preocupação em parecer inteligente, capaz ou talentoso é muito menor do que na mentalidade fixa e a autoestima não se abala facilmente com derrotas. Os 
fatores genéticos ficam em um segundo plano e não irão necessariamente decidir os resultados de uma competição ou o sucesso em uma tarefa; principalmente, quando os objetivos a serem alcançados podem ser a longo prazo.

\section{A IMPORTÂNCIA DA MENTALIDADE DE CRESCIMENTO}

De acordo com, (DUECK, 2018). A paixão pela busca de seu desenvolvimento e por prosseguir nesse caminho, mesmo e especialmente quando as coisas não vão bem, é o marco distintivo do mindset de crescimento, uma vez que as pessoas com a mentalidade de crescimento valorizam o esforço e se sentem vencedoras ao alcançar um objetivo através da dedicação encarando os desafios como oportunidades de aprendizado, permitindo que as pessoas prosperem em momentos desafiadores de suas vidas.

Desenvolver a Mentalidade de Crescimento, aprender continuamente e se adaptar às mudanças é fundamental, para o cenário em que estamos vivendo onde habilidades cognitivas estão cada vez ganhando mais valor ante a evolução da tecnologia e é preciso a habilidade para se adaptar, e a aprender continuamente, ter interesse afim de desenvolver novas habilidades.

\section{CONCLUSÃO}

O objetivo deste trabalho é contribuir para o esforço contínuo para compreender a Importância do Desenvolvimento da Mentalidade de Crescimento para o Alcance de Objetivos, o Mindset de crescimento impacta positivamente no potencial do indivíduo, dessa forma, direciona seus objetivos na busca por novos conhecimentos, desenvolvendo-se por meio do aprendizado, procurando uma oportunidade assumindo riscos, enfrentando os obstáculos como um aprendizado.

O trabalho conclui-se que a mentalidade de crescimento por si só não basta, é preciso agir, dedicar-se, ter consistência e aprender a aprender, afinal, somente encarando os desafios, errando e aprendendo é que a gente evolui.

É notável que este tema é ainda pouco explorado propõe pesquisas futuras no acerca do tema relatados neste artigo, e pode ser desenvolvido de modo significativo para agregar maior conhecimento. 
Todos temos uma mistura dessas mentalidades, a qual continua a evoluir ao longo da vida e você precisa entender que não existe uma Mentalidade puramente de crescimento ou fixa, mesmo que cultivemos a mentalidade de crescimento, ainda teremos nossos gatilhos de mentalidade fixa, que geralmente ocorrem naqueles momentos nos quais nos deparamos com desafios, recebemos críticas ou nos saímos mal em comparação com os outros. Essas situações despertam nossa insegurança ou nos colocam defensiva.

Portanto, para cultivar o Mindset de Crescimento, sair da zona de conforto e permanecer na zona de crescimento, devemos identificar e trabalhar com esses gatilhos, e ter em mente que todo sucesso é consequência de um esforço muito grande, e a conquista é a ponta de um iceberg cuja parte submersa é um conjunto de perdas e ganhos, com lutas diárias e os vários não recebidos ao longo da jornada.

Adotar postura resiliente e favorável a uma mente voltada para a adaptação não é fácil, mas é possível, é preciso prática e ter a crença verdadeira de que você pode aprender, com esforço, dedicação, quebra de paradigmas e conceitos pré-estabelecidos (por você ou pelas pessoas que fizeram, com o tempo, você acreditar que não é capaz).

\section{REFERÊNCIAS BIBLIOGRÁFICAS}

Cividini Matthiesen, Renato. (202I). HÁBITOS E DISCIPLINA. Flórida: University Must.

DUECK, C. (2018). Mindset. A nova psicologia do sucesso(r. ed.). (Objetiva, Ed., \& T. d. Duarte., Trad.) Rio de Janeiro, Rio de Janeiro, Brasil: Objetiva. Acesso em 2i de o7 de 2021, disponível em

http://repositorio.jesuita.org.br/bitstream/handle/UNISINOS/7742/Jucieli\%2oBaschi rotto_.pdf? sequence $=\mathrm{I} \&$ is Allowed $=\mathrm{y}$

DWECK, C. S. (2017). Mindset. A nova psicologia do sucesso. (Objetiva, Ed.) São Paulo, São Paulo, Brasil. Acesso em 19 de 07 de 2021, disponível em https://repositorio.ufmg.br/bitstream/r843/BUOS-

$\mathrm{BA}_{7} \mathrm{HSN} / \mathrm{r} /$ disserta_o__final___.pdf

POPOVA, M. (2014). BRAINPICKINGS. Fixo vs. Crescimento: as duas mentalidades básicas que moldam nossas vidas. Acesso em 2021 de 07 de 20, disponível em https://www.brainpickings.org/2014/oI/29/carol-dweck-mindset/ 